\title{
ЭНТОМОПАТОГЕННЫЙ ГРИБ Beauveria bassiana (Bals-Criv.) Vuill. КАК ПЕРСПЕКТИВНЫЙ БИОАГЕНТ РЕГУЛЯЦИИ ЧИСЛЕННОСТИ МАЛИННОЙ ПОБЕГОВОЙ ГАЛЛИЦЫ Resseliella theobaldi (Barnes)*
}

\author{
Т.В. ШПАТОВА', М.В. ШТЕРНШИС ${ }^{1}$, А.А. БЕЛЯЕВ ${ }^{1}$, А.А. ЛЕЛЯК ${ }^{2}$, \\ А.И. ЛЕЛЯК²
}

Малинная побеговая галлица Resseliella theobaldi (Barnes) - опасный вредитель, повреждающий малину красную (Rubus idaeus L.), одну из самых распространенных ягодных культур в мире. Для защиты растений от галлицы используют химические инсектициды, однако в последние годы подтверждена необходимость защиты ягодных культур экологически безопасными биологическими препаратами. Для насекомых отряда Diptera, к которому относится малинная побеговая галлица, наиболее подходящим биологическим агентом регуляции численности представляется энтомопатогенный гриб Beauveria bassiana (Bals-Criv.) Vuill. В настоящей работе мы впервые использовали энтомопатогенный гриб $\mathrm{B}$. bassiana в качестве агента биологической регуляции сибирской популяции малинной побеговой галлицы. Нашей целью было продемонстрировать возможности сибирского штамма гриба Beauveria bassiana в подавлении численности личинок малинной побеговой галлицы в лабораторных и полевых экспериментах на двух сортах растений малины красной. Штамм гриба B. bassiana IC-1480-25 был выделен из погибших личинок колорадского жука в Новосибирской области. В лабораторных условиях изучали влияние B. bassiana на вылет имаго насекомого из почвы, где находились личинки последнего возраста, обработанные грибом. Использовали суспензии $10^{6}-10^{7} \mathrm{KOE} /$ мл. Биологическая эффективность грибного биоагента была не ниже 80 \%. В 2015-2016 годах изучали влияние B. bassiana на вредителя в модельных полевых опытах на экспериментальных участках (СХА «Сады Сибири», Новосибирская обл.). Использовали растения малины двух сортов - Зоренька Алтая и Желтый гигант, различающихся по устойчивости к галлище. Чтобы обеспечить надежное заселение экологической ниши фитофагом и получить достоверные результаты, предварительно создавали искусственные трещины на побегах. В полевых опытах были подтверждены результаты лабораторных исследований. Действие B. bassiana зависело от погодных условий, в частности от влажности. Во влажном 2015 году сорт оказывал большее влияние на эффективность биоагента. На сорте Зоренька Алтая при обработке побегов малины грибом B. bassiana $\left(10^{7} \mathrm{KOE} /\right.$ мл) биологическая эффективность не превышала $60 \%$, на сорте малины Желтый Гигант при действии суспензии гриба в той же концентрации все личинки погибли. Полученные результаты свидетельствуют о том, что подавление малинной побеговой галлицы потенциальным агентом регуляции ее численности зависит от сорта малины, степени заселяемости трещин коры побегов вредителем, погодных условий и используемой концентрации суспензии $\boldsymbol{B}$. bassiana. Различия в численности личинок и их смертности, а также степени заселяемости трещин коры побегов вредителем в значительной степени определялись сортовыми особенностями растений малины, их реакцией на погодные условия и влиянием погодных условий на популяцию галлицы. Результаты нашего исследования подтвердили данные российских и зарубежных ученых о том, что для заметного положительного эффекта штаммов гриба боверии на насекомых отряда двукрылых концентрация грибной суспензии должна быть близка к $10^{7} \mathrm{KOE} /$ мл.

Ключевые слова: малина красная, малинная побеговая галлица, гриб Beauveria bassiana, регуляция численности, биологическая эффективность.

Малина красная (Rubus idaeus L.) - одна из самых распространенных ягодных культур в мире $(1,2)$, включая евразийский континент (3-6). К опасным организмам, паразитирующим на ней, относится малинная побеговая галлица Resseliella theobaldi (Barnes) (7-10). Самки откладывают яйца в повреждения или естественные трещины на побегах малины, после чего вылупившиеся личинки повреждают ткани стеблей. Фитофаг способен уничтожить 30-80 \% побегов малины и снизить урожай в 5-6 раз. В Западную Сибирь вредитель был завезен из европейской части бывшего СССР с посадочным материалом не позднее первой половины 1970-х годов. Здесь галлица успешно адаптировалась, сформировав местную попу-

\footnotetext{
* Работа выполнена при финансовой поддержке РНФ для Новосибирского государственного аграрного
} университета (проект № 14-16-00101). 
ляцию, и распространилась по региону, хотя была выявлена не сразу вследствие мелких размеров имаго и скрытного образа жизни личинок. В Новосибирской области галлица впервые обнаружена в 1983 году, в дальнейшем была изучена ее вредоносность и возможности подавления численности опасного фитофага (11).

Для защиты растений малины от галлицы традиционно используются химические инсектициды (12-14), основой которых служат разные классы соединений $(15,16)$. Однако все чаще высказывается озабоченность применением химических средств защиты (17) и обсуждается необходимость минимизировать пестицидные нагрузки при сохранении высокого качества продукции (18), в связи с чем внимание привлекают экологически безопасные биологические препараты, в особенности для обработки посадок ягодных культур $(19,20)$. Впервые возможность биологической регуляции численности малинной побеговой галлицы показана на примере российского бактериального препарата на основе Bacillus thuringiensis subsp. israelensis, предназначенного для контроля численности двукрылых насекомых (20). В то же время для насекомых отряда Diptera, к которому относится малинная побеговая галлица, наиболее подходящим биологическим агентом регуляции численности представляется энтомопатогенный гриб Beauveria bassiana (Bals-Criv.) Vuill. (21-24). Ранее в лабораторных условиях было установлено, что биологическая эффективность трех штаммов Beauveria bassiana, выделенных в разных географических зонах, в отношении малинной побеговой галлицы превышает 90 \% (25). В связи с тем, что галлица повреждает внутреннюю часть коры побега (паренхиму первичной коры, а также неопробковевшую перидерму), важна способность $B$. bassiana к эндофитной колонизации растений (26-29).

В настоящей работе мы впервые показали эффективность местного изолята энтомопатогенного гриба $B$. bassiana в качестве биоагента при регуляции численности сибирской популяции малинной побеговой галлицы.

Нашей целью было продемонстрировать возможности сибирского штамма гриба Beauveria bassiana в подавлении численности личинок малинной побеговой галлицы в лабораторных и полевых экспериментах на двух сортах растений малины красной.

Методика. Опыты проводили в 2015-2016 годах. Штамм гриба B. bassiana IC-1480-25 из коллекции ООО НПФ «Исследовательский центр» был выделен из погибших личинок колорадского жука в Новосибирской области. Для культивирования штамма готовили питательные среды различного состава (pH 6,5), разливали по 500 мл в колбы Эрленмейера вместимостью 2000 мл, закрывали ватно-марлевыми пробками и стерилизовали в автоклаве при температуре $121{ }^{\circ} \mathrm{C}$ в течение 40 мин. После стерилизации $\mathrm{pH}$ составляла 6,3. Охлажденную до $25{ }^{\circ} \mathrm{C}$ питательную среду засевали культурой, выращенной на картофельно-глюкозном агаре, и инкубировали на термостатируемом шейкере при $25^{\circ} \mathrm{C}$ в течение 8-10 сут.

Для лабораторной оценки действия биоагента на личинки малинной побеговой галлицы суспензию конидий гриба $\left(10^{6}\right.$ и $10^{7} \mathrm{KOE} / \mathrm{мл)} \mathrm{вно-}$ сили в пластиковые стаканчики объемом 125 мл, предварительно заполненные просеянной почвой (100 г) из-под кустов малины. Повторность опыта 4-кратная. В контрольном варианте почву в стаканчиках обрабатывали водой (25 мл). В период опыта почву систематически увлажняли (10 мл воды на стаканчик), опрыскивая поверхность из ручного пульверизатора (24). Через 14-20 сут инкубации при комнатной температуре на поверхность почвы помещали по 20 готовых к окукливанию личинок $R$. theobaldi 3-го возраста, извлеченных кисточкой из трещин на побегах малины 
с той же плантации, где брали почву. Стаканчики накрывали капроновой тканью, смазанной с внутренней стороны энтомологическим клеем Полификс (ООО ИЦ «Химтэк», Россия), на который прилипали отрождающиеся из куколок взрослые особи, и через 20 сут учитывали вылетевших из почвы имаго вредителя.

Биологическую эффективность (БЭ, \%) рассчитывали по формуле Аббота: $Б$ Э $=\left(K_{1} \cdot K_{K}\right) \cdot\left(K_{0} \cdot K_{2}\right)^{-1} \cdot 100$, где $K_{0}$ - число живых особей в опыте до обработки, $K_{1}$ - число живых особей в опыте после обработки, $K \kappa-$ число живых особей в контроле до обработки, $K_{2}-$ число живых особей в контроле после обработки.

Влияние энтомопатогенного гриба $B$. bassiana на личинок галлицы в модельных полевых опытах (экспериментальные участки плантаций малины, СХА «Сады Сибири», Новосибирская обл., 2015-2016 годы) на растениях малины двух сортов - Зоренька Алтая (относительно устойчив к галлице) и Желтый гигант (неустойчив к повреждению вредителем). Использовали суспензии гриба в концентрациях $10^{6}$ и $10^{7} \mathrm{KOE} /$ мл. Эталоном служил химический инсектицид Искра-М («Техноэкспорт», Россия), контролем - необработанные побеги малины. Оценивали число личинок на одну трещину и их гибель, рассчитывали биологическую эффективность биоагента.

Чтобы обеспечить надежное заселение экологической ниши фитофагом и получить достоверные результаты, предварительно создавали искусственные трещины на побегах. Для этого на побеге на высоте 30-50 см от поверхности почвы препаровальной иглой делали по одному порезу длиной около $10 \mathrm{~cm}$, чтобы привлечь самок галлицы. У искусственной трещины отслаивали полосу эпидермиса 1-2 мм для образования кармана, в который имаго галлицы производила яйцекладку, после чего в этот же день побеги обрабатывали суспензией гриба. Использовали ранцевый опрыскиватель марки Orion-Kwazar («Kwazar Corporation Sp. z o.o.», Польша) при норме расхода рабочей жидкости 500-1000 л/га. Через 2 нед после обработки биоагентом срезали по 5-6 маркированных побегов, подсчитывали общее число личинок на одну трещину и число погибших личинок.

Обработку полученных данных проводили с помощью компьютерных программ ANOVA и Microsoft Excel 2010. Рассчитывали средние значения $(M)$ и стандартные ошибки средних $( \pm \mathrm{SEM})$. Для выявления статистической значимости различий использовали $t$-критерий Стьюдента; данные считали значимыми при р $<0,05$ (30).

Результаты. В лабораторном опыте по определению влияния энтомопатогенного гриба $B$. bassiana в двух концентрациях на малинную побеговую галлицу наблюдалось статистически достоверное $(\mathrm{p}<0,05)$ снижение числа вылетевших имаго по отношению к контролю. Биологическая эффективность грибного биоагента в использованных концентрациях $\left(10^{6}\right.$ и $10^{7} \mathrm{KOE} /$ мл) была не ниже $80 \%$ (табл. 1).

1. Отрождение имаго малинной побеговой галлицы Resseliella theobaldi (Barnes) при обработке энтомопатогенным грибом Beauveria bassiana (Bals-Criv.) Vuill. (лабораторный опыт)

\begin{tabular}{|c|c|c|c|}
\hline \multirow[b]{2}{*}{ Вариант } & \multicolumn{2}{|c|}{ Выход имаго } & \multirow[b]{2}{*}{$\begin{array}{l}\text { Биологическая } \\
\text { эффективность, \% }\end{array}$} \\
\hline & $\begin{array}{l}\text { экз., в среднем } \\
\text { на вариант } M \pm \text { SEM) }\end{array}$ & $\begin{array}{l}\text { к исходной } \\
\text { численности личинок, \% }\end{array}$ & \\
\hline Контроль & $14,3 \pm 0,7$ & & \\
\hline B. bassiana, $10^{6} \mathrm{KOE} /$ мЛ & $2,8 \pm 0,6$ & 13,8 & 80,5 \\
\hline B. bassiana, $10^{7} \mathrm{KOE/мл}$ & $1,3 \pm 0,5$ & 6,3 & 91,0 \\
\hline
\end{tabular}

Эти результаты соответствуют данным, полученным в лаборатор- 
ных испытаниях со штаммами боверии $\left(10^{7} \mathrm{KOE} / \mathrm{M}\right)$, которые были выделены Б.А. Борисовым (25) в трех географически удаленных местностях России и Украины.

2. Плотность заселения личинками малинной побеговой галлицы Resseliella theobaldi (Barnes) коры (экз. на трещину) на растениях малины двух сортов при обработке энтомопатогенным грибом Beauveria bassiana (Bals-Criv.) Vuill. и химическим инсектищидом ( $M \pm \mathrm{SEM}, \mathrm{CXA}$ «Сады Сибири», Новосибирская обл.)

\begin{tabular}{|c|c|c|c|c|c|c|c|c|}
\hline \multirow{3}{*}{ Вариант } & \multicolumn{4}{|c|}{ Число личинок, эКз. } & \multirow{2}{*}{\multicolumn{2}{|c|}{ Смертность, \% }} & \multirow{2}{*}{\multicolumn{2}{|c|}{$\begin{array}{l}\text { Биологическая } \\
\text { эффективность, \% }\end{array}$}} \\
\hline & \multicolumn{2}{|c|}{ всего } & \multicolumn{2}{|c|}{ живых } & & & & \\
\hline & 2015 год & 2016 год & 2015 год & 2016 год & 2015 год & 2016 год & 2015 год & 2016 год \\
\hline \multicolumn{9}{|c|}{ Сорт Зоренька Алтая } \\
\hline Контроль & $6,0 \pm 0,9$ & $14,6 \pm 0,1$ & $4,3 \pm 0,1$ & $10,4 \pm 0,2$ & 28,3 & 28,8 & & \\
\hline B. bassiana, $10^{6} \mathrm{KOE} /$ мл & $5,1 \pm 0,7$ & $5,2 \pm 0,2^{\mathrm{ab}}$ & $0,8 \pm 0,2^{\mathrm{a}}$ & $1,0 \pm 0,3^{\mathrm{ab}}$ & 84,3 & 80,8 & 54,0 & 52,0 \\
\hline B. bassiana, $10^{7} \mathrm{KOE/мЛ}$ & $5,7 \pm 0,7$ & $5,5 \pm 0,2^{\mathrm{ab}}$ & $0,7 \pm 0,3^{\mathrm{a}}$ & $0,9 \pm 0,2^{\mathrm{ab}}$ & 87,7 & 83,6 & 57,6 & 54,9 \\
\hline Искра-М, 0,2 \% & $6,8 \pm 1,0$ & $7,4 \pm 0,1^{\mathrm{ac}}$ & $0,4 \pm 0,2^{\mathrm{a}}$ & $0,1 \pm 0,1^{\mathrm{ac}}$ & 94,1 & 98,8 & 70,2 & 70,0 \\
\hline \multicolumn{9}{|c|}{ Сорт Желтый Гигант } \\
\hline Контроль & $9,1 \pm 2,8$ & $16,8 \pm 0,2$ & $8,2 \pm 0,1$ & $13,0 \pm 0,2$ & 9,9 & 22,6 & & \\
\hline B. bassiana, $10^{6} \mathrm{KOE} /$ мл & $11,9 \pm 3,3^{b}$ & $3,4 \pm 0,4^{\mathrm{ab}}$ & $6,1 \pm 0,2^{\mathrm{a}}$ & $1,0 \pm 0,3^{\mathrm{a}}$ & 48,5 & 70,6 & 39,5 & 48,0 \\
\hline B. bassiana, $10^{7} \mathrm{KOE/мЛ}$ & $7,7 \pm 2,9$ & $2,7 \pm 0,5^{\mathrm{ab}}$ & 0 & $0,7 \pm 0,3^{\mathrm{a}}$ & 100,0 & 74,1 & 77,1 & 51,5 \\
\hline Искра-М, 0,2 \% & $5,0 \pm 3,7$ & $8,0 \pm 0,4 \mathrm{ac}$ & 0 & 0 & 100,0 & 100,0 & 90,1 & 77,4 \\
\hline
\end{tabular}

Результаты лабораторных исследований подтвердились в полевых опытах в 2015-2016 годах (табл. 2). В 2015 году на сорте Зоренька Алтая при обработке побегов малины грибом B. bassiana в двух концентрациях наблюдалось статистически достоверное снижение числа личинок по отношению к контролю ( $<20,05)$, число живых личинок не превышало 1 экз. на трещину. Биологическая эффективность достигала 54,0-57,6 \%. При использовании химического препарата Искра М число живых личинок не превышало 0,4 экз. на трешину, их гибель достигала $94 \%$, биологическая эффективность $-70,0 \%$. На сорте Желтый Гигант после обработки побегов суспензией гриба живые личинки были обнаружены только при использовании B. bassiana в концентрации $10^{6} \mathrm{KOE} / \mathrm{Mл.} \mathrm{В} \mathrm{варианте} \mathrm{с}$ концентрацией суспензии $10^{7} \mathrm{KOE} /$ мл все личинки погибли. Биологическая эффективность энтомопатогенного гриба $\left(10^{7} \mathrm{KOE} /\right.$ мл) была достаточно высокой, хотя не достигала соответствующей величины при действии химического инсектицида. В 2016 году результаты, полученные на малине сорта Зоренька Алтая, практически не отличались от данных предыдущего года. На растениях сорта Желтый Гигант столь резких различий в действии разных концентраций гриба, как в предыдущий год, не наблюдали (см. табл. 2). По-видимому, выбор сорта оказывает определенное влияние на активность B. bassiana вследствие разной привлекательности для вредителя. Известно также, что действие грибных препаратов зависит от погодных условий, в частности, от влажности. Поскольку 2015 год был более влажным, это могло привести к повышению эффективности грибного биоагента на растениях малины сорта Желтый Гигант, неустойчивого к повреждению галлицей.

Полученными нами данными подтверждаются результаты других ученых $(22,24,31-33)$, свидетельствующие, что для заметного положительного эффекта штаммов боверии на насекомых отряда Diptera концентрация грибной суспензии должна быть не ниже $10^{7} \mathrm{KOE} /$ мл. При этом отметим, что в имеющихся публикациях представлены результаты только лабораторных испытаний. Так, при заражении in vitro личинок, куколок и имаго мексиканской плодовой мухи Anastrepha ludens (Loew) бразильским, мексиканским и эквадорскими штаммами B. bassiana значимая гибель 
продемонстрирована только для взрослых насекомых (22). Показано, что в лабораторных условиях при контактном и пероральном заражении боверией (10 8 КОЕ/мл) взрослых особей оливковой мухи Bactrocera oleae (Gmelin) гибель насекомых достигала 50 \% (24). Три штамма B. bassiana в лабораторных условиях были протестированы на куколках луковой мухи Delia antiqua (Meigen) (Diptera: Anthomyiidae). При концентрации гриба 107 KOE/мЛ гибель насекомых составляла 35,4-52,5 \% (33). Также in vitro показано влияние штаммов B. bassiana на пупарии и имаго плодовой мухи Ceratitis capitata (Wiedemann) (Diptera: Tephritidae). При этом штамм B. bassiana Bb1333 вызывал более 50 \% гибели этих насекомых (31). Кроме того, упоминается о выделении боверии из того же насекомого в Бразилии (32). Данных о влиянии этого грибного агента биоконтроля на малинную побеговую галлицу как in vitro, так и in vivo в литературе мы не обнаружили. Известная способность гриба $B$. bassiana распространяться под корой растений (34), скорее всего, способствует его действию как биоагента при регуляции численности малинной побеговой галлицы, что показало и наше исследование.

Таким образом, в лабораторных и полевых условиях продемонстрирована возможность биологического контроля малинной побеговой галлицы Resseliella theobaldi сибирским штаммом гриба Beauveria bassiana. Показано, что подавление вредителя потенциальным агентом регуляции его численности зависит от сорта малины, погодных условий и концентрации B. bassiana (концентрация грибной суспензии должна быть близка к $\left.10^{7} \mathrm{KOE} / \mathrm{M}\right)$. Различия в численности личинок и их смертности, а также в заселяемости трещин коры побегов в большей степени определяются сортовыми различиями растений малины, их реакцией на погодные условия и влиянием погодных условий на популяцию галлицы.

\section{ЛИТЕРАТ УРА}

1. Williams I.H. Effects of environment on Rubus idaeus L. V. Dormancy and flowering of the mature shoot. Journal of Horticultural Science, 1960, 35(3): 214-220 (doi: 10.1080/00221589.1960.11513985).

2. Казаков И.В. Малина и ежевика. М., 2001.

3. Кичина В.В. Крупноплодные малины России. М., 2005.

4. Jennings S.N., Brennan R.M. Improvement of raspberry cultivars in Scotland. Acta Horticulturae, 2002, 585: 179-183 (doi: 10.17660/ActaHortic.2002.585.27).

5. Sønsteby A., Heide O.M. Environmental control of growth and flowering of Rubus idaeus L. cv. Glen Ample. Scientia Horticulturae, 2008, 117(3): 249-256 (doi: 10.1016/j.scienta.2008.05.003).

6. Woznicki T.L., Heide O.M., Remberg S.F., Sønsteby A. Effects of controlled nutrient feeding and different temperatures during floral initiation on yield, berry size and drupelet numbers in red raspberry (Rubus idaeus L.). Scientia Horticulturae, 2016, 212: 148-154 (doi: 10.1016/j.scienta.2016.09.047).

7. Labanowska B.H., Cross J. Raspberry cane midge - Resseliella theobaldi (Barnes) - flight and egg laying dynamics on raspberry fruiting on two year old canes. Journal of Fruit and Ornamental Plant Research, 2008, 16: 315-323

8. Vetek G., Fail J., Penzes B. Susceptibility of raspberry cultivars to the raspberry cane midge (Resseliella theobaldi Barnes). Journal of Fruit and Ornamental Plant Research, 2006, 14(Suppl. 3): 61-66.

9. Беляев А.А., Шпатова Т.В., Штерншис М.В. Феромониторинг малинной побеговой галлицы Resseliella theobaldi (Barnes). Сельскохозяйственная биология, 2010, 3: 113-117.

10. Tanasković S., Milenković S. Monitoring of flight phenology of raspberry cane midge Resseliella theobaldi Barnes (Diptera: Cecidomyiidae) by pheromone traps in Western Serbia. Acta Entomologica Serbica, 2010, 15(1): 81-90.

11. Сидорович А.С., Беляев А.А., Белова Л.Б. Малинная побеговая галлица и пурпуровая пятнистость в Новосибирской области. В сб.: Товарное ягодоводство: организация, технологии, сортимент. Бердск, 1990: 28-31.

12. Dalman P., Malkki S. Experiments on chemicals and cultural control of the raspberry cane midge (Resseliella theobaldii) and midge blight. Annales Agriculturae Fenniae, 1986, 25(4): 233-241. 
13. Прокофьев М.А. Защита садов Сибири от вредителей. М., 1987.

14. Milenković S., Retenović D., Antonijević M. Raspberry gall midge Resseliella theobaldi (Barnes) (Diptera: Cecidomyidae) - harmfulness and control. Journal of Yugoslav pomology, 2004, 38(34): $191-198$.

15. Williamson B. Effect of fenitrothion and benomyl sprays on raspberry cane midge (Resseliella theobaldi) and midge blight, with particular reference to Leptosphaeria coniothyrium in the disease complex. Journal of Horticultural Science, 1987, 62(2): 171-175 (doi: 10.1080/14620316.1987.11515766).

16. Labanowska B.H., Cross J. Raspberry cane midge - flight dynamics, eggs laying and the efficacy of neonicotinoid insecticide acetamiprid on primocane fruiting raspberry. IOBC/wprs Bulletin, 2008, 39: 19-25.

17. Gordon S.C., Woodford J.A.T., Birch A.N.E. Arthropod pests of Rubus in Europe: pest status, current and future control strategies. Journal of Horticultural Science, 1997, 72(6): 831-862 (doi: 10.1080/14620316.1997.11515577).

18. Birch A.N.E., Gordon S.C., Fenton B., Malloch G., Mitchel C., Jones A.T., Griffiths D.V., Brennan R., Graham J., Woodford J.A.T. Developing a sustainable IPM System for high value Rubus crops (Raspberry, Blackberry) for Europe. Acta Horticulturae, 2004, 649: 289-292 (doi: 10.17660/ActaHortic.2004.649.54).

19. Штерншис М.В. Биологическая защита растений в Сибири. Защита и карантин растений, 2013, 4: 19-22.

20. Mohamedova M. Field evaluation of three biopesticides for control of the raspberry cane midge Resseliella theobaldi (Barnes) in Bulgaria. Advances in Horticultural Science, 2017, 31(3): 183-189 (doi: 10.13128/ahs-20575).

21. Shternshis M.V., Belyaev A.A.., Shpatova T.V., Bokova J.V., Duzhak A.B. Field testing of Bacticide $^{\circledR}$, Phytoverm ${ }^{\circledR}$ and Chitinase for control of the raspberry midge blight in Siberia. BioControl, 2002, 47(6): 697-706 (doi: 10.1023/A:1020574914831).

22. De la Rosa W., Lopez F. L., Liedo P. Beauveria bassiana as a pathogen of the Mexican fruit fly (Diptera: Tephritidae) under laboratory conditions. Journal of Economic Entomology, 2002, 95(1): 36-43 (doi: 10.1603/0022-0493-95.1.36).

23. Ekesi S., Dimbi S., Maniania N.K. The role of entomopathogenic fungi in the integrated management of fruit flies (Diptera: Tephritidae) with emphasis on species occurring in Africa. In: Use of entomopathogenic fungi in biological pest management /S. Ekesi, N.K. Maniania (eds.). Kerala, India, 2007: 136-172.

24. Mahmoud M.F. Pathogenicity of three commercial products of entomopathogenic fungi, Beauveria bassiana, Metarhizum anisopilae and Lecanicillium lecanii against adults of olive fly Bactrocera oleae (Gmelin) (Diptera: Tephritidae) in the laboratory. Plant Protection Science, 2009, 45(3): 98-102 (doi: 10.17221/34/2008-PPS).

25. Штерншис М.В., Шпатова Т.В., Борисов Б.А., Беляев А.А. Влияние энтомопатогенных гифомицетов и препарата Фитоверм ${ }^{\circledR}$ на малинную побеговую галлицу (Resseliella theobaldi) и возбудителя пурпуровой пятнистости малины (Didymella applanata). Микология $u$ фитопатология, 2005, 39(1): 76-82.

26. Ownley B.H., Pereira R.M., Klingeman W.E., Quigley N.B., Leckie B.M. Beauveria bassiana, a dual purpose biocontrol organism, with activity against insect pests and plant pathogen. In: Emerging concepts in plant health management /R.T. Lartey, A.J. Caesar (eds.). Research Signpost, Kerala, 2004: 255-269.

27. Posada F.J., Vega F.E. Establishment of the fungal entomopathogen Beauveria bassiana (Ascomycota: Hypocreales) as an endophyte in cocoa seedlings (Theobroma cacao). Mycologia, 2005, 97(6): 1195-1200 (doi: 10.1080/15572536.2006.11832729).

28. Vega F.E. Insect pathology and fungal endophytes. Journal of Invertebrate Pathology, 2008, 98(3): 277-279 (doi: 10.1016/j.jip.2008.01.008)

29. Ownley B.H., Gwinn K.D., Vega F.E. Endophytic fungal entomopathogens with activity against plant pathogens: ecology and evolution. BioControl, 2010, 55(1): 113-128 (doi: 10.1007/s10526009-9241-x).

30. Доспехов Б.А. Методика полевого опыта (с основами статистической обработки результатов исследований). М., 1985.

31. Quesada-Moraga E., Ruiz-García A., Santiago-Álvarez C. Laboratory evaluation of entomopathogenic fungi Beauveria bassiana and Metarhizium anisopliae against puparia and adults of Ceratitis capitata (Diptera: Tephritidae). Journal of Economic Entomology, 2006, 99(6): 1955-1966 (doi: 10.1093/jee/99.6.1955).

32. Ekesi S., Maniania N.K., Lux S.A. Mortality in three African tephritid fruit fly puparia and adults caused by the entomopathogenic fungi, Metarhizium anisopliae and Beauveria bassiana. Biocontrol Science and Technology, 2002, 12(1): 7-17 (doi: 10.1080/09583150120093077).

33. Poprawski T.J., Robert P-H., Boivin I.M. G. Susceptibility of Delia antiqua (Diptera: Anthomyiidae) to eleven isolates of entomopathogenic hyphomycetes. Environmental Entomology, 1985, 14(5): 557-561 (doi: 10.1093/ee/14.5.557).

34. Kreutz J., Zimmermann G., Vaupel O. Horizontal transmission of the entomopathogenic fun- 
gus Beauveria bassiana among the spruce bark beetle, Ips typographus (Col., Scolytidae) in the laboratory and under field conditions. Biocontrol Science and Technology, 2004, 14(8): 837-848 (doi: 10.1080/788222844).

\title{
1ФГБОУ ВО Новосибирский государственный Поступила в редакцию аграрный университет,
} 630039 Россия, г. Новосибирск ул. Добролюбова, 160, e-mail: tshpatova@ngs.ru $\bowtie$, shternshis@mail.ru, belyaev.an.ar@gmail.com; $200 О$ НПФ «Исследовательский иентр»,

630559 Россия, Новосибирская обл., Новосибирский р-н, наукоград Кольцово, промзона, корпус 200, e-mail: leliak1@yandex.ru, leliak2@yandex.ru

\section{ENTOMOPATHOGENIC FUNGUS Beauveria bassiana (Bals-Criv.) Vuill. AS A PROMISING AGENT FOR THE RASPBERRY CANE MIDGE Resseliella theobaldi (Barnes) BIOCONTROL}

\author{
T.V. Shpatova1, M.V. Shternshis', A.A. Belyaev', A.A. Lelyak², A.I. Lelyak ${ }^{2}$
}

\author{
${ }^{1}$ Novosibirsk State Agrarian University, 160, ul. Dobrolubova, Novosibirsk, 630039 Russia, e-mail tshpatova@ngs.ru \\ ( $₫$ corresponding author), shternshis@mail.ru, belyaev.an.ar@gmail.com; \\ ${ }^{2}$ OOO NPF Research Center, 200, promzona, Koltsovo Science Town, Novosibirsk Region, Novosibirsk Province, \\ 630559 Russia, e-mail leliak1@yandex.ru, leliak2@yandex.ru \\ ORCID: \\ Shpatova T.V. orcid.org/0000-0002-0022-4309 \\ Shternshis M.V. orcid.org/0000-0002-9660-1606 \\ Belyaev A.A. orcid.org/0000-0003-2461-0762 \\ The authors declare no conflict of interests \\ Acknowledgements: \\ Supported financially by the grant of Russian Science Foundation for Novosibirsk State Agrarian University (pro- \\ ject No. 14-16-00101) \\ Received July 8, 2018 \\ Lelyak A.A. orcid.org/0000-0002-6822-8015 \\ Lelyak A.I. orcid.org/0000-0001-8219-9559 \\ doi: 10.15389 /agrobiology.2019.3.505eng
}

\section{Abstract}

Red raspberry Rubus idaeus L. is a widespread crop including Eurasian continent. This berry crop is often damaged by the dangerous pest, the raspberry cane midge Resselliella theobaldi (Barnes). This insect pest commonly destroys 30-80\% of raspberry canes and decreases berry yield 5-6-fold. Chemical insecticides predominate in raspberry plant protection against the pest. However, the trend of recent years lays in replacement of chemicals for ecologically safe biological agents, especially for soft fruit plant protection. The entomopathogenic fungus Beauveria bassiana (Bals-Criv.) Vuill. is a well-known agent for biocontrol of Diptera insects, including the cane midge. In this paper for the first time we have used a Siberian isolate of $B$. bassiana as a biological agent for regulation of Siberian population of this dangerous pest of the red raspberry. The aim of the research was to demonstrate capability of Siberian B. bassiana strain to suppress the number of raspberry cane midge in the laboratory and in the field conditions for two red raspberry cultivars. B. bassiana strain IC1480-25 was isolated from Colorado beetle dead larvae in Novosibirsk region. In the laboratory the influence of $B$. bassiana was studied by counting of adults flying from soil where larvae of last instar were treated with entomopathogenic fungus at $10^{6}-10^{7} \mathrm{CFU} / \mathrm{ml}$ concentration. Laboratory test efficacy was more than $80 \%$. In 2015-2016 the impact of B. bassiana on $R$. theobaldi was studied in the field conditions (plantation of Siberian Garden, Novosibirsk region). Raspberry cultivars Altai Zorenka (cv. 1) and Yellow Giant (cv. 2) differed in the susceptibility to the insect were field tested. In order to provide a reliable occupancy of ecological niche by phytophagous insect and to obtain reliable results, the artificial cane splits were created before the strain application. The results of field test were in line with the laboratory experiments. The B. bassiana activity depended on weather conditions, particularly on humidity. In the more humid 2015, the contrast between two varieties in response to $B$. bassiana was more pronounced. The efficacy of treatment with $10^{7} \mathrm{CFU} / \mathrm{ml}$ fungal suspension was less than $60 \%$ for cv. 1 and $100 \%$ (all larvae died) for cv. 2. The results of this research evidence that the suppression of raspberry cane midge by the potential biocontrol agent depends on berry cultivar, weather conditions and B. bassiana dose. Larvae number and their mortality as well as degree of bark splits occupancy is mainly determined by the differences in raspberry variety and their response to weather changes, and also by the impact of weather on insect population. These results confirm the data of Russian and foreign researchers that $10^{7} \mathrm{CFU} / \mathrm{ml}$ concentration of B. bassiana provides a marked effect on Diptera pests.
\end{abstract}

Keywords: red raspberry, raspberry cane midge, fungus Beauveria bassiana, pest number regulation, biological efficacy. 